\title{
The Prioritization of Verb over Subject in Teaching the Sentence Structure
}

\author{
Imran Muhammad ${ }^{1} \&$ Mamuna Ghani ${ }^{2}$ \\ ${ }^{1}$ Govt. Postgraduate College, Burewala, Pakistan \\ ${ }^{2}$ The Department of English, The Islamia University of Bahawalpur, Pakistan \\ Correspondence: Imran Muhammad, Govt. Postgraduate College, Burewala, Pakistan. E-mail: \\ imranchuhan@hotmail.com
}

Received: May 19, 2017 Accepted: September 21, 2017 Online Published: November 24, 2017

doi:10.5539/ijel.v8n1p257ＵRL: https://doi.org/10.5539/ijel.v8n1p257

\begin{abstract}
The prior contribution of present study is its focus on verb rather than subject in commencing teaching sentence structure. Firstly, this paper deals with a detailed analysis of stative and dynamic verbs and stipulates how the difference between subject and agent comes down to is, by projection on the part of either stative verb or dynamic verb. Secondly, in Pakistan where more often than not, ELT practices in class rooms from grass root level to master's level look to grammar translation method, two theta roles i.e. subject and agent are conspicuous by their absence. Therefore, this paper reasons out their absence and the difficulty, in explaining the subject and agent, faced by the teaching staff members working in schools and colleges in the south southern part of Punjab, Pakistan. Finally, the study culminated that the teaching of verb prior to subject is sine qua non for teaching the sentence structure.
\end{abstract}

Keywords: stative verb, dynamic verb, utilization, identification, subject, agent

\section{Introduction}

Neither the syntax nor is the semantics of the subject NP a reliable source of determining the subject and agent. In point of fact, the meaning of verb is the sole determinant of the subject and agent in a simple active sentence (not passive). Stative and dynamic are the semantic based types of verb and have appeared as role assigners. Both types of verb correlate with the subject and agent respectively, that is to say the subject agrees in theta role with the verb. This type of agreement is called notional. This stipulation outflanks Coppola \& Newport (2005) who stressed on the need of a single semantic correlate associated with the roles taken on by the subject.

In Pakistan where English is taught as a second language, it is a matter of opinion that the teaching of subject and its agent counterpart is a matter of concern to the teachers serving in schools and colleges. If it comes to the point, the teachers divide the sentence into the subject and predicate and tend to commence the teaching of sentence structure with the description of subject prior to verb and happen to define the subject as the doer of an action. They see no semantic difference between both he's in "he broke the window" and "he is a boy". In point of fact, the former is the subject that functions as an agent and latter is the subject.

The present study is a survey that reports on the way the teaching staff members serving in the schools and colleges of the province of Punjab, Pakistan, start teaching the sentence structure with the description of either the subject or the verb (predicate). They seem to be entangled in defining the subject and agent on the account that they look at the subject NP on syntactic level and tend to define it as doer of an action only.

\subsection{Difference between Stative verb and Dynamic verb}

Smith (1991) suggests that English main verbs are classified as states and events. According to him, the events are dynamic which involve change, activity and role of agent whereas the states are static which denote the occurrence of an event with no end point. Nevertheless, in case of dynamic verbs, usually the subject (agent) transits its action through the verb onto the object as in "Lucas drank water". Imran et al. (2016, p. 122) suggest that a verb may be stative if the process of its occurrence (be) demonstrates spontaneity as grew in "the crops grew rapidly". 


\subsection{Role of Verb in the Identification of Subject and Agent}

Chomsky (1981) suggests that the number, type and position of the theta role assigned by a lexicon must be satisfied in syntactic structure following the Projection Principle (p. 38). In English, a subject may appear as the subject or the agent. All subjects cannot be agents but all agents are necessarily subjects. A subject in itself is not a subject or an agent; it is the semantics of the verb which determines the role of the subject NP as subject or agent. If the meaning the verb shows spontaneity in the occurrence of an event, the verb is categorized as stative on syntactic level which projects the subject NP to function as the subject as Lucas in "Lucas grew young". The stative verb "grew" projects that "Lucas" must be a subject, not an agent.

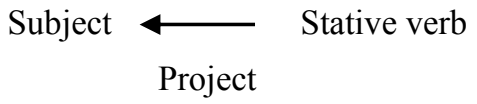

Similarly, if the meaning of the verb shows some action, the verb is categorized as dynamic which projects the subject NP to function as the agent as Lucas in "Lucas kicked the football". The verb "kicked" projects the subject "Lucas" to function as an agent.

Agent Dynamic verb

Project

Illustration (3) corroborates the process of teaching the difference between subject and agent. The process runs from semantics to syntax, the reversal of which will result in failure to explain a difference between the two. The semantics of the verb labels it either dynamic or stative on syntactic level and ultimately, in an active sentence, the former projects the agent and the latter projects the subject on syntactic level.

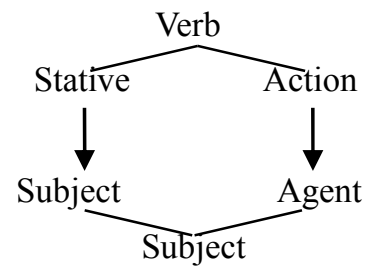

\subsection{Subject-verb Agreement}

Formal agreement (conjugation) between the subject and verb looks familiar in which the projection directs from the left to the right (clockwise) that is, in a simple active sentence, the verb usually finds its way into the sequence of the words on the right side of the subject and agrees with the latter in person and number. For example, verb forms am and is are selected in accordance with first and third person (subject) respectively. Similarly, there are specific verb forms to correspond with singular and plural persons e.g., the girls pluck some flowers and the girl plucks some flowers.

However, in case of notional agreement between the subject and verb, the direction is always from right to left (anti clockwise) that is, in a simple active sentence, the subject agrees with the verb through projection principle (see illustrations $1 \& 2$ ). Hence, unlike object-verb agreement, the subject and verb agree reciprocally with each other whereby the verb agrees with the subject and vice versa.

\section{Literature Review}

Every English sentence has a subject (S) and verb (V) and quite a few have an object (O) also. Hence, a lot of constructions exhibit subject-verb agreement and every so often, object-verb agreement. The Emeritus Professor of English Algeo and her husband Thomas Pyles conclude that agreement occurs when a word changes its form depending on the other words to which it relates (2009). However, different researchers hold different views regarding the nature of subject-verb agreement. Bock \& Miller (1991) and Bock (1995) suggest that in English, subject-verb agreement is entirely syntactic in nature; that is, the processes that ensure subject-verb agreement typically operate over a syntactic representation. Whereas Vigliocco \& Garrett (1996) opine that subject-verb agreement in English is essentially notional. They argue that in other languages, such as Spanish, verb agreement is likely to be semantic in nature. However, Cervel \& Mendoza Ibanez (2005) were of the view that agreement may be formal and notional as well. The former is based on grammatical category whereas the latter is based on meaning.

Nevertheless, Nicol \& Greth (2003) conducted experiments to find out the types of errors the second language learners produce regarding the subject-verb agreement in Spanish as a second language. Eighteen native English speakers, who were enrolled at the University of Arizona, participated in the study. The findings of their study 
revealed that both English-dominant learners of Spanish and Spanish-dominant speakers of English developed a tendency to implement agreement in a particular way in their native language. Their study culminated in a perception that semantically-based (notional) subject-verb agreement appeared as result of a number of factors.

Therefore, the researchers' focus has been on seeking out some semantic correlation associated with the subject that may help isolate it from its agent counterpart. But the conclusions of several research studies reveal that there is still a gap for some fixed criteria that may help identify when an NP is a subject and when it is an agent. For example, Keenan (1976) reported that no fixed criteria exist to categorically identify a noun phrase as a subject, but a set of common, multidimensional criteria can be applied across languages. Later on, Comrie (1989) and Jackendoff (1990) concluded that important for the present studies is the lack of a semantically constant value associated with the subjects. Coppola \& Newport (2005) also harped on the same string and reported that grammatical subjects are found almost in every language of the world and that, the subjects are often found functioning as agents and that, all the subjects are not necessarily agents. They were of the view that the subjects in different constructions may take different thematic roles and that; subjects do not have a single semantic correlate that may differentiate between the roles taken on by subjects.

However, the present study brings out semantically-based (notional) agreement (the missing link) between the subject and verb whereby stative verb always projects the subject and dynamic verb projects the agent in a simple active sentence (see illustration 3). Add to this, the correlation between the subject and verb helps facilitate the teaching of subject and its agent counterpart. This stipulation brings out the fact that the teaching of verb prior to subject is a convenient way of teaching the sentence structure. Hence, the role of stative verbs and dynamic verbs cannot be denied in differentiating the subject from its agent counterpart. In the countries like Pakistan where English is taught as a second language, for the most often, the concept of subject and agent becomes an enigma wherever the teaching of subject precedes that of verb.

To find out how many teaching staff members serving in the schools and colleges face difficulty in elaborating the subject and agent in the wake of commencing the teaching of sentence structure with the description of subject prior to verb, and to get at other factors which add to their difficulty, a survey was conducted among the teaching staff members in Punjab, Pakistan.

\section{Research Methodology}

\subsection{The Questionnaire}

For data collection, a questionnaire composed of two parts was wielded. Part I of the questionnaire consisted of seven sentences in which blanks were left to be filled in. The participants were asked to tick mark one of the options that appear against each sentence.

Four sentences (4-7) were chosen as indicators to judge the validity of option (c) in (3) if marked. The participants were asked to mark one of the two options i.e. a) subject or b) subject plus agent. The results of option (c) in (3) were included only when any two of the indicators were marked accordingly e.g. (b) in (4 \& 6) and (a) in (5 \& 7).

Part II consisted of three sentences. The participants were asked to mark one of the two options i.e. a) agree or b) disagree. Furthermore, bold typefaces served their turn for emphasis. Sentence (8) was designed as a tester to judge the reliability of the participants' inasmuch as (a) in (8) being identical to (b) in (4-7) was a guide. However, the results of (8) were not included in the study. Option (a) in (9) \& (10) collaboratively served as participants' realization of getting on with the matter in hand.

\subsection{Participants}

69 college staff members and 129 school teachers from Arifwala, Bahawalnagar and Burewala participated in the present study. They were both male and female associate professors, assistant professors, lecturers and teachers from the state run as well as private institutions.

\subsection{Data Manipulation}

The responses to the questionnaire were analyzed via descriptive statistics. The formula of percentage was applied to evaluate the data. For the purpose of this study, the analysis focused on the percentage of the options marked with tick to get at: (i) the element of grammar the teaching staff members give priority to in commencing the teaching of sentence structure; (ii) the source they rely on to determine the subject and agent; (iii) a more general label they give to the subject in a simple active sentence; (iv) and the number of respondents entangled in perplexity in dealing with the subject and agent. 


\section{Results}

The questionnaire unveils four possible outcomes displayed in Table 1, 2, $3 \& 4$ one after the other.

Table 1. Percentage of the element of grammar given priority to in commencing teaching the sentence structure

\begin{tabular}{lll}
\hline Element & Number of respondents & Percentage \\
\hline Subject & 133 & $67 \%$ \\
Verb & 65 & $33 \%$ \\
\hline
\end{tabular}

It follows from the data in Table 1 that the majority of the teaching staff members showed a strong tendency to start the teaching of sentence structure with the description of subject prior to verb. It means that the majority tended to put the cart before the horse.

Table 2. Percentage of the individual sources relied on to determine the subject

\begin{tabular}{lll}
\hline Source & Number of respondents & Percentage \\
\hline Sequence of words & 106 & $54 \%$ \\
Meaning of $1^{\text {st }}$ word & 54 & $27 \%$ \\
Meaning of verb & 38 & $19 \%$ \\
\hline
\end{tabular}

Table 2 exposes the fact that the number of the respondents who employed meticulous technique to determine the subject and agent was far less than those who backed the wrong horse. It means that the alarming increase in failure was due to their dependency on the distractors rather than the meaning of verb. Table 3 expounds that the teaching staff members who defined the subject accordingly were in lesser number.

Table 3. Percentage of the label given to the subject in an active sentence

\begin{tabular}{lll}
\hline Label & Number of respondents & Percentage \\
\hline Doer & 122 & $62 \%$ \\
Passive & 38 & $19 \%$ \\
Both Doer and Passive & 38 & $19 \%$ \\
\hline
\end{tabular}

The empirical data in Table 4 reveals that to more than half of the teaching staff members, the dual role of subject NP in English active sentence constructions was a matter of concern. The data also reveals that the number of the college staff members was more than that of school teachers who realized of getting on with the matter in hand. However, the situation was more complicated than they had at first realized.

Table 4. Percentage of the participants entangled in dealing with subject

\begin{tabular}{llll}
\hline Institution & Participants in toto & Entangled in difficulty & Percentage \\
\hline College & 69 & 49 & $71 \%$ \\
School & 129 & 64 & $50 \%$ \\
\hline Total & 198 & 113 & $57 \%$ \\
\hline
\end{tabular}

\section{Discussion}

First off, the results derived from the questionnaire show that both the college staff members and school teachers seemed to be entangled in difficulty in dealing with the subject in English active sentences. The feedback unveils the fact that they were perplexed by the dual role taken on by the subject which they needed to tackle. The reason behind their difficulty was that the majority tended to commence the teaching of the sentence structure with the description of subject prior to verb. Add to this the majority looked to the sequence of words in sentences in order to determine the subject and constrained the definition of subject to "the doer of an action". On account of these reasons, their technique of determining the subject seemed debunked.

Firstly, the teaching of subject prior to verb drove a coach and horses through their technique. The data reveals that $67 \%$ of the respondents were in favor of commencing the teaching of sentence structure with the description of subject prior to verb while those who went in favor of teaching the verb prior to subject were $33 \%$ only. The 
reason of fall in number of the latter was marked with their tendency to look at the subject syntactically rather than semantically. For them, the subject finds its way into the sequence of words prior to verb. Nevertheless, the duality in the role of subject is essentially a semantic based quality therefore; their prioritization bore hard on them.

Secondly, another reason of difficulty in dealing with the subject and its agent counterpart was their reliability on the distractors rather than the meaning of verb in determining the subject. According to the data, $54 \%$ of the respondents considered "the sequence of words" as a reliable source of labeling the subject NP as subject or agent and $27 \%$ of the staff members showed a tendency to rely on "the meaning of first element" of sentence for the same. Both the groups said much the same thing, meaning thereby that more than $80 \%$ of the respondents flogged a dead horse because neither the sequence of words nor is the meaning of first word, of an active sentence, a guide to recognize the subject NP as subject or agent. The meaning of first element (NP) in Julie ate an apple and Julie is a girl is same despite the fact that the former sentence has an agent and the latter has a subject.

Nevertheless, it is the meaning of the verb that serves to determine the role of subject NP as the subject or agent. In other words, two kinds of verb i.e., stative verb and action verb are the only reliable source of recognizing the subject and agent. If the meaning of verb labels it as a dynamic verb, it becomes corroborative for the function of subject NP as an agent and if the semantic of verb labels it as a stative verb, it projects the subject (see 1.2). It is evident from the data that only $19 \%$ of the staff members showed a tendency to rely on "the meaning of verb" to determine the subject and agent in an active sentence. It means that a much smaller number of respondents employed the technique accordingly.

Thirdly, the technique they employed for dealing with the subject fell down while horsing around with defining labels. According to the data, $62 \%$ of the respondents constrained the definition of the subject to mere doer and $19 \%$ to passive only. Taken collectively, more than $80 \%$ of the teaching staff members tended to confine the definition of subject to either doer or passive which resulted in failure in their technique to determine the subject and agent.

Hence, the definition of subject is inclusively (= including doer of action and passive) more than the sum of its parts. Meaning thereby, it is unfair to label the subject as mere doer and not passive and vice versa. A subject can appear as doer (Susan watered the plants) or passive (Susan grew old) in English sentence constructions.

Lastly, the data reveals that the teaching staff members were facing difficulty in dealing with the subject and its agent counterpart. $57 \%$ of the respondents realized of getting on with the matter in hand. The percentage of college staff members and school teachers in this regard were $71 \%$ and $50 \%$ respectively. It means that the higher the level was, the more debunked their technique was. What was all about that? It was all about the weakness in their technique for determining the subject or agent.

Hence, the analysis revealed that the teaching of subject prior to verb, defining the subject as doer and dependency on the sequence of words to determine the subject and agent were the main premises of the technique employed by the teaching staff members in teaching subject-agent difference. It means that their prioritization of subject, inadequate labeling to subject and improper way of determining the subject and agent collaborated to debunk their technique. As a result, the teaching staff members fall a prey to perplexity in dealing with the subject and agent in English active sentences inasmuch as their technique of describing both the roles was debunked.

All they needed to do was to ameliorate their technique for dealing with the subject and agent. For example, they needed to: (i) commence the teaching of sentence structure with the description of verb prior to subject; (ii) define the subject inclusively (= including doer of action and passive); and (iii) look to the meaning of verb which serves to change horses in mid-stream.

This stipulation goes on with Imran et al. (2016, p. 123) who are of the view that the flow of information or the word order determines the subject of a sentence; as well as is corroborated by the theories propounded by Pollard \& Sag (1994) and Miller (2011) in which they argue over taking the subject to be the complement of verb (predicate). In Pakistan, more often than not, ELT practices in class rooms from grass root level to the master's level look to Grammar Translation Method (GTM) where each aspect of grammar is looked at from semantic point of view, the absence of one or both the theta roles i.e. the subject and agent seems weird and eerie. However, the present study stipulates how the difference between the subject and agent comes down to is, by the projection on the part of stative verb and dynamic verb respectively. The present stipulation outperforms the old speculation that important for the present studies is the lack of a semantically constant value associated with the subjects propounded by Comrie (1989) and Jackendoff (1990). 
However, the present study stipulates in detail that the role of verb is very much there in the identification of the subject and its agent counterpart. Stative verbs always project the subject and dynamic verbs project the agent on the left in simple active sentences in English. "A dynamic verb usually has a subject which functions as an agent that transits its action (behavior) through the verb onto the object and that a verb may be stative if the process of its occurrence demonstrates spontaneity" (Imran et al., 2016, p. 122). The above discussion finally illumines that the prioritization of verb over the subject facilitates the teaching of the sentence structure. The study also corroborates that the teaching staff members serving in different schools and colleges situated in the south southern part of Punjab, Pakistan were facing difficulty in the description of the subject and agent due to several weaknesses in their technique employed for teaching the sentence structure. Their technique was debunked mainly because of their prioritization of the subject over the verb.

\section{Conclusion}

It must be said, in view of the data, that the tendency to teach subject prior to verb prevails in the schools and colleges situated in the south southern part of Punjab, Pakistan. As a result, the teaching staff members come across difficulty in explaining the difference between subject and its agent counterpart. Hence, two kinds of verb i.e. stative verb and dynamic verb serve as theta role assigners and help facilitate the description of the subject and agent through projection. Therefore, the teaching of sentence structure should commence with the description of verb prior to that of subject.

Additionally, the present study serves to introduce two theta role assigners and their requirements, and thus, shun the old notion that "the subjects do not have a single semantic correlate" (Coppola \& Newport, 2005).

\section{References}

Algeo, J., \& Pyles, T. (2010). The origins and development of the English language. Boston, MA: Wadsworth Cengage Learning.

Bock, J. K., \& Miller, C. A. (1991). Broken agreement. Cognitive Psychology, 23, 35-43. https://doi.org/10.1016/0010-0285(91)90003-7

Bock, K. (1995). Producing agreement. Current Directions in Psychological Science, 4(2), 56-61. https://doi.org/10.1111/1467-8721.ep10771165

Cervel, M. S. P., \& de Mendoza Ibáñez, F. J. R. (Eds.). (2005). Cognitive linguistics: Internal dynamics and interdisciplinary interaction (Vol. 32). Walter de Gruyter.

Chomsky, N. (1981). Lectures on Government and Binding, Foris, Dordrecht. Chomsky Lectures on Government and Binding 1981.

Comrie, B. (1989). Language Universals and Linguistic Typology: Syntax and Morphology. Chicago: University of Chicago Press.

Coppola, M., \& Newport, E. L. (2005). Grammatical subjects in home sign: Abstract linguistic structure in adult primary gesture systems without linguistic input. Proceedings of the National Academy of Sciences of the United States of America, 102(52), 19249-19253. https://doi.org/10.1073/pnas.0509306102

Imran, M., Asgher, T., \& Ghani, M. (2016). A Study on Science Students' Understanding of Three Lemmas: State Verb, Action Verb and Noun in the State Run Colleges in Pakistan. International Journal of English Linguistics, 6(5), 121. https://doi.org/10.5539/ijel.v6n5p121

Jackendoff, R. (1990). Semantic Structures. Cambridge, MA: MIT Press.

Keenan, E. L. (1976). Towards a universal definition of "subject". In C. N. Li (Ed.), Subject and Topic (pp. 304-333). London: Academic Press.

Miller, J. E., \& Miller, J. (2011). A critical introduction to syntax. London: A\&C Black.

Nicol, J., \& Greth, D. (2003). Production of subject-verb agreement in Spanish as a second language. Experimental psychology, 50(3), 196. https://doi.org/10.1026//1617-3169.50.3.196

Pollard, C., \& Sag, I. A. (1994). Head-driven phrase structure grammar. Chicago: University of Chicago Press.

Smith, C. (1991). The Parameter of Aspect. Dordrecht: Kluwer. http://dx.doi.org/10.1007/978-94-015-7911-7

Vigliocco, G., \& Garrett, M. F. (1996). Subject-verb agreement in Spanish and English: Differences in the role of conceptual constraints. Cognition, 61(3), 261-298. https://doi.org/10.1016/S0010-0277(96)00713-5 


\section{Appendix A}

\section{The Questionnaire}

\section{Part 1}

1. The teaching of sentence structure (grammar) should start with
a. subject
b. verb

2. In an active sentence, the "subject" can appear as
a. doer
b. passive
c. both

3. It is the that helps recognize the first word of an active sentence as a subject or an agent.
a. sequence of words
b. meaning of 1 st word
c. meaning of verb

4. The first element (Julie) in the sentence "Julie eats an apple" is
a. subject
b. subject + agent

5. The first element (Julie) in the sentence "Julie is a girl" is
a. subject
b. subject + agent

6. When an active sentence contains an action verb, the first element (NP) of the sentence is called
a. subject
b. subject + agent

7. When an active sentence contains a stative verb, the first element (NP) of the sentence is called
a. subject
b. subject + agent

\section{$\underline{\text { Part } 2}$}

8. An agent can be a subject.
(a). agree
(b). disagree

9. A subject is always the doer of an action.
(a). agree
(b). disagree

10. In "Julie is a girl", the subject (Julie) is not doing any action.
(a). agree
(b). disagree

\section{Copyrights}

Copyright for this article is retained by the author(s), with first publication rights granted to the journal.

This is an open-access article distributed under the terms and conditions of the Creative Commons Attribution license (http://creativecommons.org/licenses/by/4.0/). 